\title{
Bailout procedures during percutaneous transluminal angioplasty of superficial femoral artery occlusive disease
}

\author{
El-Sayed Afifi Abd El-Mabood*, Omar Ahmed Elkashef, Ahmed Samir Hosny and Hossam Zaghloul
}

\begin{abstract}
Background: Though uncommon, complications of endovascular angioplasty and stenting may have devastating outcomes that can threaten limb and life. Adequate awareness of these complications will allow to achieve excellent clinical outcomes.

Results: Endovascular intervention was successful in treatment of most of distal SFA complications with limited use in flush ostial complications; residual stenosis $\geq 30 \%$, flow-limiting dissection, perforation or rupture; 100\% in group (2) vs 50\% in group (1) but thrombosis; $75 \%$ of distal SFA lesions were treated endovascularly vs $40 \%$ of flush ostial lesions; $X^{2}=12.7, P=0.02$. Emergency surgery as a bailout was used for most ostial lesion complications: residual stenosis $\geq 30 \%$, flow-limiting dissection, and perforation or rupture; $50 \%$ in group (1) vs $0 \%$ in group (2); $X^{2}=20.1$, $P=0.01$.
\end{abstract}

Conclusion: Bailout procedures are procedures used to save the limb or the patient. Evolving endovascular strategies embrace new technologies in an attempt to improve the safety and efficacy of revascularization procedures for lower extremity arterial occlusive disease.

Keywords: SFA occlusive disease, Percutaneous transluminal angioplasty, Bailout procedures

\section{Background}

As in every therapeutic procedure, endovascular procedures such as angioplasty and stenting carry an inherent risk of complication to the patient. Though with the proper training, these complications can usually be successfully managed endovascularly, and improper management may lead to emergency surgery, limb loss, functional disability, and death. It is paramount that physician operators have the proper training and ability to anticipate, recognize, and treat complications as they arise during endovascular procedures [1].

\footnotetext{
* Correspondence: elsayedafifi@yahoo.com

The present manuscript is a revised submission to previous submission number (EJRNM-D-18-00125) after response to both reviewers and resubmitted again on December 22, 2018, with number (EJRNM-D-18-00471) and was withdrawn due to change of publisher.

Vascular unit, Departments of General Surgery, Cairo University, Giza 13511,
} Egypt

Springer Open

(c) The Author(s). 2020 Open Access This article is licensed under a Creative Commons Attribution 4.0 International License, which permits use, sharing, adaptation, distribution and reproduction in any medium or format, as long as you give appropriate credit to the original author(s) and the source, provide a link to the Creative Commons licence, and indicate if changes were made. The images or other third party material in this article are included in the article's Creative Commons licence, unless indicated otherwise in a credit line to the material. If material is not included in the article's Creative Commons licence and your intended use is not permitted by statutory regulation or exceeds the permitted use, you will need to obtain permission directly from the copyright holder. To view a copy of this licence, visit http://creativecommons.org/licenses/by/4.0/. stenting in the femoral artery appears to show decreased complications with stent utilization. Complex lesions such as occlusions, associated with longer procedure times, and frequent equipment manipulations, may predispose to higher rates of complication than those seen in the treatment of simple stenotic lesions [2].

Endovascular treatment options have evolved since the 1990s to become the first-line treatment of lower extremity occlusive disease in many instances despite a meta-analysis of superficial femoral artery angioplasty versus exercise therapy in patients with intermittent claudication found in similar 3- and 6-month quality of life outcomes, but improved ankle to brachial index in those with endovascular intervention [3].

Balloon angioplasty and stents expand the scope of patients who are eligible for treatment of infrainguinal occlusive disease. Several newer techniques are developing 


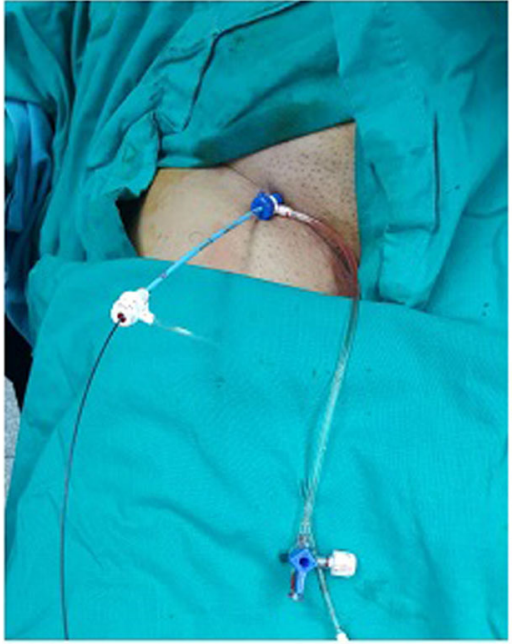

(a): Contralateral with crossover

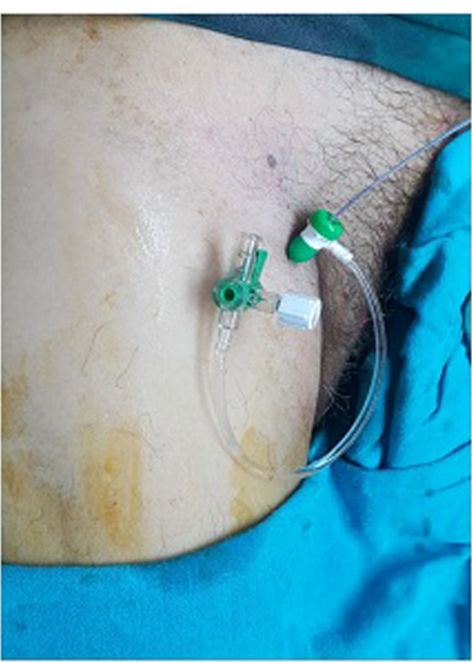

(b): Antegrade ip silateral puncture.

Fig. 1 Femoral axis. Either a Contralateral retrograde femoral axis with crossover sheath insertion to the left or $\mathbf{b}$ Antegrade ipsilateral femoral axis to the right

that substantially increase the spectrum of treatment options. Endovascular infrainguinal techniques are most useful in patients who are poor candidates for open surgery and in those with focal short segment disease [4].

Limb-salvage patients have also shown a higher procedural complication rate than claudicants. When endovascular complications do occur, over $86 \%$ are usually evident in the angiographic suite, and almost all are evident within a 5-h postprocedure. As in all procedures, it is proper training and anticipation of the potential for a complication that will be most likely to prevent it [5].
Acute vascular complications at the endovascular procedure site include arterial perforation, dissection, thrombosis, spasm, side branch occlusion, and equipment failure. Arterial perforation can occur both at the site of balloon angioplasty and distally from the guidewire. Perforation has been reported in $0-2.3 \%$ of patients [6].

Flow-limiting dissections and residual stenoses of 30\% greater occur with an estimated combined frequency of $10 \%$. Endovascular stents have diminished the clinical impact of even large intimal dissections. Since stents can effectively treat a dissection, most clinically relevant dissections occur either during guidewire placement or

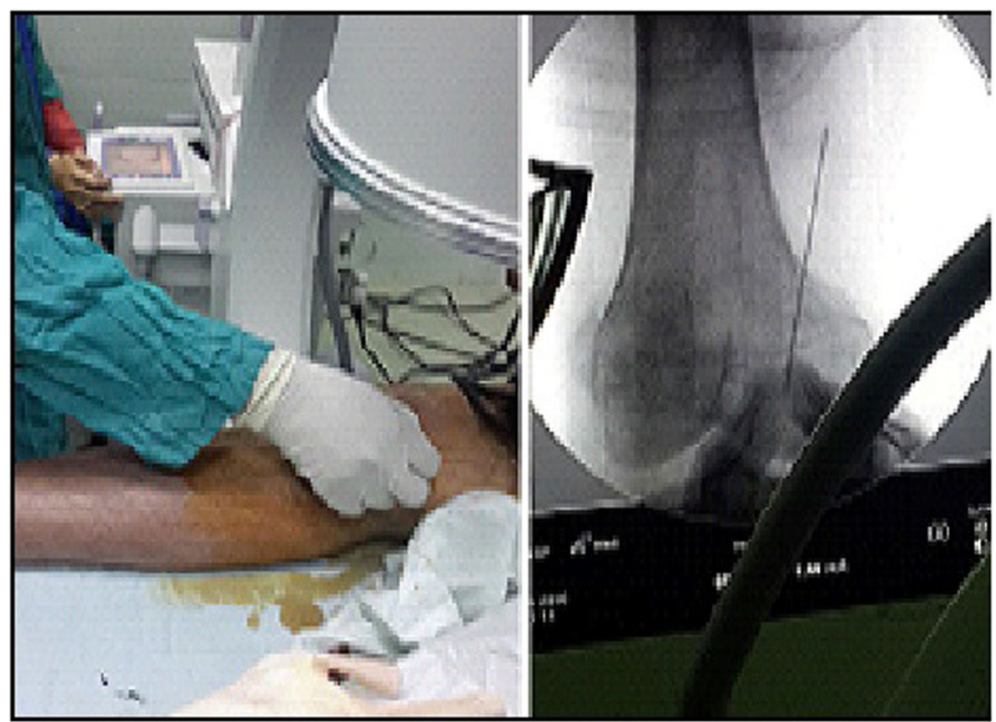

Fig. 2 Transpopliteal access 


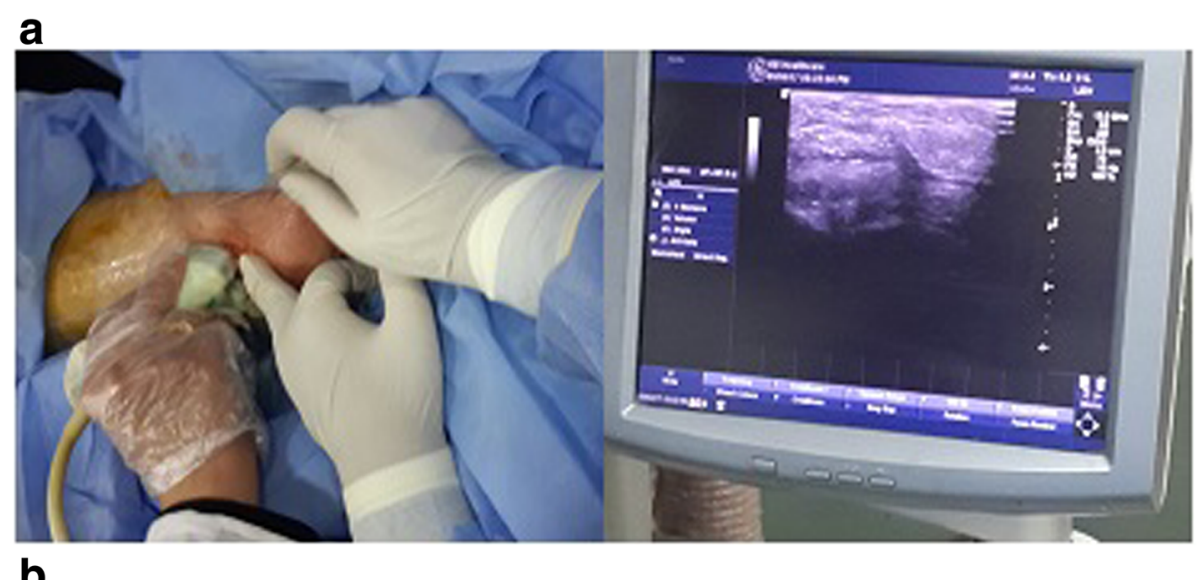

b
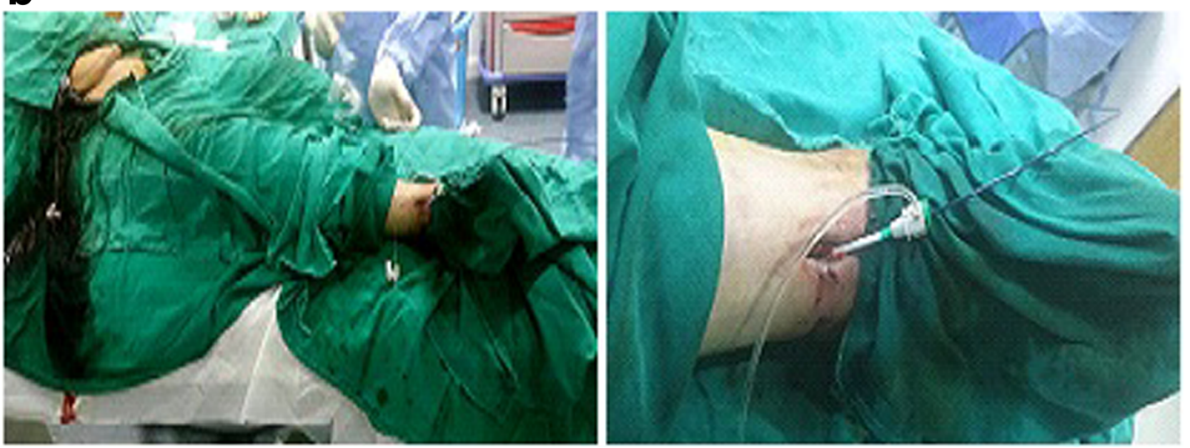

Fig. $\mathbf{3}$ a, b Transtibial access were used as bailout procedures

from unrecognized and untreated dissection after wire removal [7].

Arterial spasm rarely leads to a serious complication during angioplasty; however, severe symptoms of pain may occur. The occurrence of arterial vessel spasm appears to be more common in younger patients. Another source of procedural complication is related to device failure. This includes angioplasty balloon rupture prior to stent expansion, stent embolization, guidewire fracture, and catheter fracture $[8,9]$.

The main aim of this study was to review the results of bailout procedures during percutaneous transluminal angioplasty of superficial femoral artery occlusive disease as regards the disease location in superficial femoral artery (ostial lesions vs. other segment lesions) and types of immediate complications (residual stenosis $\geq 30 \%$, flow-limiting dissection, perforation, or thrombosis).

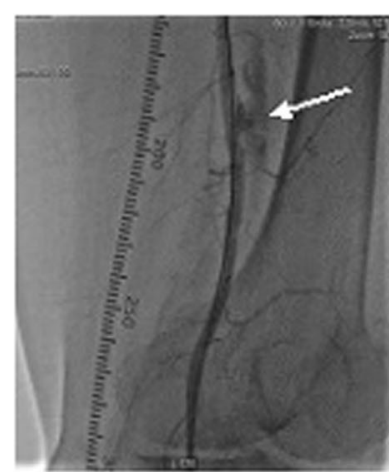

Perforation

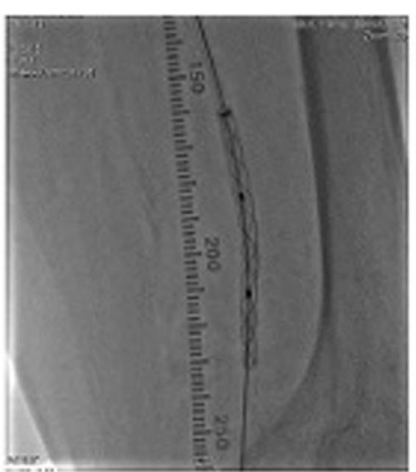

Corered stent

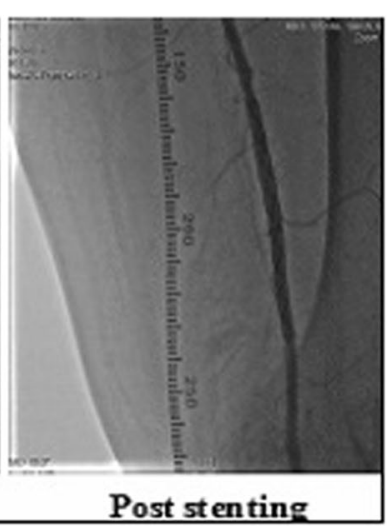

Post stenting

Fig. 4 Bailout procedures for perforation 


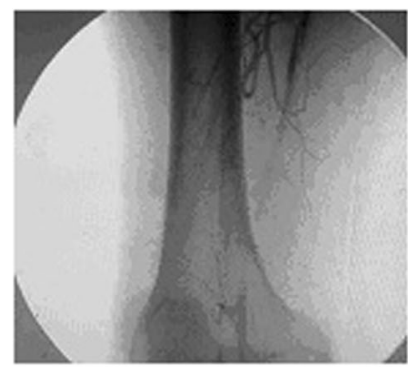

Thrombosis

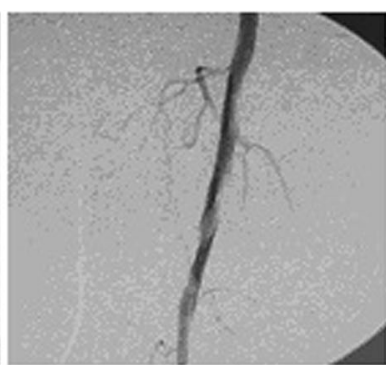

Dissection

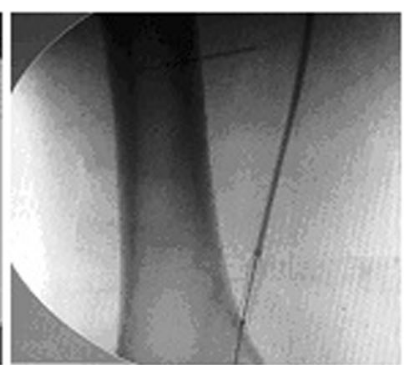

Stenting

Fig. 5 Bailout procedures for thrombosis and dissection

\section{Methods}

Patients undergoing treatment for symptomatic superficial femoral artery (SFA) occlusive were considered for inclusion in this study from November 2015 until September 2017. This is a retrospective study that was conducted on 30 patients complaining of lower limb ischemia: Rutherford class 3 to 6 clinically and with superficial femoral artery occlusive disease TASC II type $\mathrm{A}$ and $\mathrm{B}$ lesions.

Patients were distributed into two groups according to the disease location: group 1: ostial lesions $(n=10)$ and group 2: other segment lesions $(n=20)$. All were studied for immediate complications that occurred during the percutaneous transluminal angioplasty of superficial femoral artery occlusive disease and needed bailout procedures to save the limb or the patient; these complications included residual stenosis $\geq 30 \%$, flow-limiting dissection, perforation or rupture, thrombosis, equipment failure, arterial spasm, or device embolization.

All patients underwent evaluation by complete history taking then full clinical examination, and preprocedural investigations included duplex scanning and $\mathrm{CT}$ angiography before intervention to detect the site and extent of the disease and the ABI. Evaluation of associated comorbidities by ECG or ECHO Doppler was performed.

\section{Bailout procedures}

Patients were admitted 1 day before or on the day of the procedure. All interventions were done in angio suite (Philips; Allura X per FD 20/722028164) and C-arm

Table 1 Patients' demographic data

\begin{tabular}{|c|c|c|c|c|}
\hline \multirow[t]{2}{*}{ Data } & & & \multicolumn{2}{|l|}{ Findings } \\
\hline & & & Number (\%) & Mean \pm SD (range) \\
\hline \multirow[t]{3}{*}{ Age (years) } & Strata & $41-55$ & 11 (36.7\%) & $46.3 \pm 5.2$ \\
\hline & & $\geq 55$ & 19 (63.3\%) & $61.7 \pm 6.9$ \\
\hline & Total & & $30(100 \%)$ & \\
\hline \multirow[t]{2}{*}{ Gender } & Female & & $10(33.3 \%)$ & \\
\hline & Males & & $20(66.7 \%)$ & \\
\hline
\end{tabular}

Data are presented as numbers, mean $\pm S D$, and percentages image intensifier with road mapping was used. Patients were placed in supine position. Both groins were prepared using antiseptic solution povidone iodine (10\%). All interventions were done under local anesthesia (lidocaine $2 \%, 3-5 \mathrm{mg} / \mathrm{kg}$ ) and sometimes combined with sedation in irritable patients.

The arterial access was planned after reviewing of the preoperative imaging; The SFA was accessed through either antegrade ipsilateral common femoral artery puncture or contralateral retrograde femoral puncture and performing a crossover technique (Fig. 1). The choice out of the above options depended on the anatomy and operator preference. In cases of failure of the previous 2 accesses, retrograde ipsilateral puncture of the popliteal artery where the patient lies on supine or lateral decubitus position (Fig. 2) or transtibial access were used as bailout procedures (Fig. 3a, b).

After gaining access, a standard $6 \mathrm{~F}$ sheath was inserted, and free arterial flow is allowed to confirm the

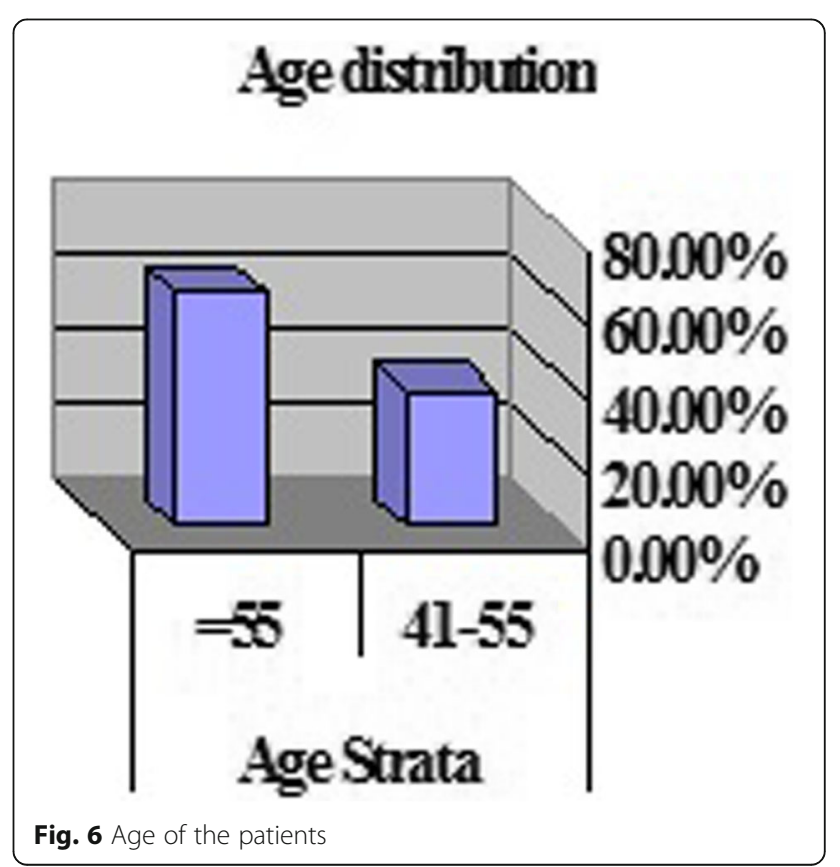




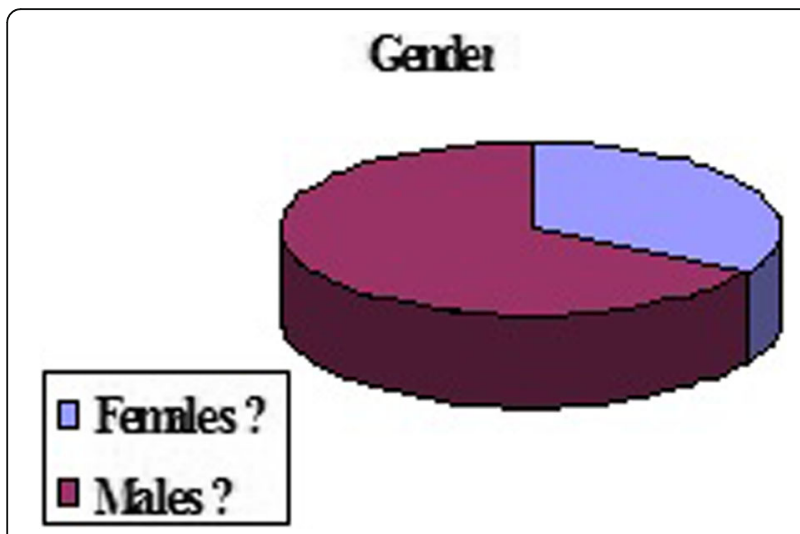

Fig. 7 Gender of the patients

right position of the sheath. Angiography was done to confirm data obtained by preoperative investigations and SFA lesions were identified using nonionic low osmolar dye diluted to $50 \%$ with normal saline. Systemic anticoagulation was given as follows: heparin IV 5000 IU initially and then $8-10 \mathrm{IU} / \mathrm{kg} / \mathrm{h}$ and $1000 \mathrm{IU}$ per $500 \mathrm{ml}$ of flushing solution to prevent wires, sheath, and thrombosis.

Crossing the lesion was done by different techniques and equipment being individualized according to each case but the standard tools for recanalization of stenosis and occlusions consisted of a 0.035-inch hydrophilic guidewires (standard type (Terumo Wire, Terumo) for stenosis and stiff type (Terumo Wire, Terumo) for CTO and an angled-tip angiographic catheter (4F or 5F Bernstein; Angiodynamic, Soft $\mathrm{Vu}$ or vertebral; Medtronic). Guidewires were used for crossing the lesion transluminal or subintimal.

The proximal occlusion was penetrated and followed by negotiation to the full extent of the occlusion until the distal patent lumen. A drilling motion of the guidewire was performed to properly penetrate and cross the lesion. Often times, a short and low profile coaxial catheter balloon size 3-4 $\mathrm{mm}$ can be used as a support catheter. Once the lesion has been crossed, the catheter should be advanced beyond the lesion, and the wire removed and contrast were injected to ensure that the catheter was within the lumen.
Then, a balloon catheter (5-6 mm; Admiral xtreme, INVAtec) selected for appropriate diameter (5 or 6 $\mathrm{mm}$ ) and length was advanced over the wire to the distal extent of the lesion. The balloon was inflated until any waist on the balloon has been abolished. The inflation time was standardized; inflation times vary from $30 \mathrm{~s}$ to $3 \mathrm{~min}$.

Prior to inflation of the balloon, the patient should be warned that they may experience pain, although this should not be excessive. As the balloon inflates, assessment of the roadmap image should confirm that the balloon catheter was appropriately sized. If there was excessive pain or the balloon looks too big, the balloon was exchanged for a smaller diameter balloon.

After balloon deflation, the balloon catheter was withdrawn slightly, and the balloon catheter should be reinflated with overlaps until the whole lesion had been covered. The balloon catheter was withdrawn completely, while keeping the guidewire in place across the lesion.

Angiography to assess the result was performed by injecting contrast medium through the side arm of the sheath. There should be rapid forward flow through the treated segment with no residual stenosis greater than $30 \%$. Dissections in the wall of the artery were expected and did not imply a poor result unless they were flow limiting.

Acute complications that needed bailout procedures included arterial perforation, dissection, thrombosis, residual stenosis $\geq 30 \%$, spasm of distal arteries, device embolization, and equipment failure. Arterial perforation could occur both at the site of balloon angioplasty and distally from the guidewire. When there were complications, bailout procedures started and depended on the disease location and the type of complications and included open surgical exposure for most ostial lesion complications. bailout procedures for other segment complications included balloon dilatation by lager diameter balloon, stenting, or surgery (bypass or interposition graft) for residual stenosis $\geq 30 \%$ or flow-limiting dissection. But for perforation or rupture, balloon tamponade covered stent (Fig. 4) or surgical intervention by

Table 2 Presenting symptoms of the studied patients

\begin{tabular}{llll}
\hline Data & & Findings \\
\cline { 3 - 4 } & & Number (\%) & Mean \pm SD (range) \\
\hline Presenting symptoms according to Rutherford categories & Category $\mathbf{3}$ & $5(6.7)$ & $16.7)$ \\
& Category $\mathbf{4}$ & $7(23.3)$ & $1.2 \pm 0.8(0.5-2)$ \\
& Category $\mathbf{5}$ & Category $\mathbf{6}$ & Duration of symptoms (months) \\
& &
\end{tabular}


interposition graft, bypass surgery, vein patch, or direct closure.

For thrombosis, if the patient was critically affected, thrombectomy was done during the angioplasty by fogarty over the wire or open surgical thrombectomy. But if the patient was not critically affected, thrombolytic therapy was applied via Uni Fuse catheter (Angiodynamics); 15,40 , or $50 \mathrm{~cm}$ or fontaine catheter (Boston Scientific); and 30 or $50 \mathrm{~cm}$ (according the length affected), i.e., tissue plasminogen activator (actylase, 50 $\mathrm{mg}$ ) (2 bottles, one powder and another solution of 50 $\mathrm{ml}: 10 \mathrm{ml}$ loading dose was injected followed by flush saline before application of the occluding wire then $0.01-0.05 \mathrm{mg} / \mathrm{kg} / \mathrm{h}$ maintenance dose $(1 \mathrm{ml} / \mathrm{h}$ till $40 \mathrm{~h}$; this dose was monitored using fibrinogen level to avoid serious bleeding) with heparin ampoule IV every 4-6 h or continuous infusion $500 \mathrm{iu} / \mathrm{h}$; then imaging and managing according to findings.

In arterial spasm, vasodilator agent (nitroglycerine, 50-100 $\mu \mathrm{g}$ ) was administered; and occasionally, a guidewire may have to be removed to distinguish refractory spasm from dissection. But if there was device embolization, it was removed by vascular snare and grasping forceps.

In equipment failure, failed balloon deflation (air lock) was managed with continuous negative pressure with endoflator or a large $(20 \mathrm{ml}$ or larger) syringe but if failed to pass into sheath, the balloon was punctured from outside to rupture it and withdrawn into the sheath with rotation to fold its wings. Balloon herniation was treated by traction to the catheter during inflation; but if failed, this problem was solved by using a longer balloon. Balloon rupture was managed by switching to another balloon using its shoulder for dilatation, but if this balloon ruptured, switch to a thicker and more puncture-resistant polymer balloon; a stent was applied and the lesion through the stent was dilated; if this
Table 3 Risk factors and co-morbidities of the studied patients

\begin{tabular}{lll}
\hline Data & Findings & \\
\cline { 2 - 3 } & No & $\%$ \\
\hline Diabetic & 17 & 56.7 \\
Hypertensive & 22 & 73.3 \\
Previous ischemic heart disease & 2 & 6.7 \\
Previous stroke & 1 & 3.3 \\
Smoking & 25 & 83.3 \\
More than one co-morbid & 16 & 51.7 \\
\hline
\end{tabular}

Data are presented as numbers, mean $\pm S D$, and percentages

balloon ruptured on the end of the stent, the balloon was replaced by another one, and the end of the stent was dilated last. The balloon catheter did not track along the standard guidewire; this wire was exchanged for a stiffer guidewire and the balloon tracked if failed tracking; long sheath was applied.

Stent insertion was done in the patients where there were elastic recoil (if the balloon inflates fully, but the stenosis persists) and a flow-limiting dissection (Fig. 5); prolonged balloon inflation can be performed to (tack down) the flap. If this fails, other presentations such as recurrent lesions after a recent PTA or long segment occlusions or a self-expanding stent was used $(5$ or $6 \mathrm{~mm}$, Everflex, ev3). The stent should not be oversized relative to the diameter of the SFA. The stent should be long enough to cover the lesion with $5-10 \mathrm{~mm}$ coverage of the normal artery on either side of the lesion.

Then, auxiliary procedures like tibial angioplasty were performed when needed to enhance and augment the outflow vessels using the following tools: previously used 0.035 -inch hydrophilic guidewires or 0.018-inch guidewire "Boston Scientific V-18 $8^{\mathrm{m} \text { " }}$ control wire for tibials, and 0.014 inch guidewire "Abbott Pilot ${ }^{\mathrm{m} \mathrm{m})}$ for pedal arteries. Long tibial balloons low-profile with diameters from

\section{Risk factors \& co-morbidities}

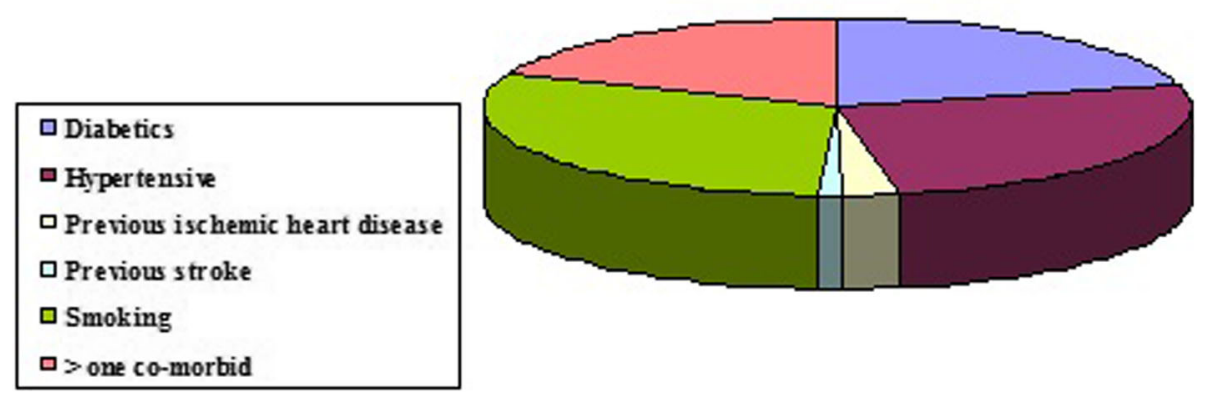

Fig. 8 Risk factors and co-morbidities of the studied patients 
2 or $3 \mathrm{~mm}$ (less than $4 \mathrm{~F}$ ) designed for tibial angioplasty purposes "Amphirion/Invatec, Admiral." They are made to work on a $0.035,0.014$, "or a 0.018 inch". The wire is left across the lesion for access and an intra-arterial nitroglycerin $(50-100 \mu \mathrm{g})$ is given, and a check angiogram is performed, and redilatation is done whenever required.

The endpoint of the procedure was unrestricted forward flow of contrast with no evidence of significant (>30\%) residual stenosis. The runoff was assessed at the end of the procedure for the occurrence of distal embolization caused by the PTA or stent insertion. Lastly, PTA of any relevant tibial lesions is performed during the same procedure (patients are being treated for critical ischemia). When the procedure was completed, the arterial access sheath was removed immediately, when more than $5000 \mathrm{IU}$ of heparin was given, and the sheath removal was delayed until aPTT normalizes. Hemostasis was achieved by manual compression. Digital compression was held proximal to the skin puncture site for $15-20 \mathrm{~min}$, and mobilization was delayed for $6-12 \mathrm{~h}$.
Table 4 Lesion characteristics of the studied patients

\begin{tabular}{llll}
\hline \multirow{2}{*}{ Lesion characteristics } & \multicolumn{2}{c}{ Findings } \\
\cline { 3 - 4 } & & No & $\%$ \\
\hline Location & Flush ostial lesions & 10 & 33.3 \\
\multirow{2}{*}{ Length } & Other segment lesions & 20 & 66.7 \\
\multirow{2}{*}{ Type } & TASC $(\mathbf{A})<\mathbf{1 0} \mathbf{~ c m}$ & 13 & 43.3 \\
& TASC $(\mathbf{B})<\mathbf{1 5} \mathbf{~ c m}$ & 17 & 56.7 \\
Number & Stenosis & 14 & 46.7 \\
& CTO & 16 & 53.3 \\
Runoff & Single & 19 & 63.3 \\
& Multiple & 11 & 36.7 \\
Access type used & Single & 8 & 26.7 \\
& Multiple & 22 & 73.3 \\
Procedure used & Retrograde contralateral femoral & 16 & 53.3 \\
& Antegrade ipsilateral femoral & 14 & 46.7 \\
& Balloon angioplasty & 13 & 43.3 \\
& Stenting & 17 & 56.7
\end{tabular}

Data are presented as numbers, mean $\pm \mathrm{SD}$, and percentages

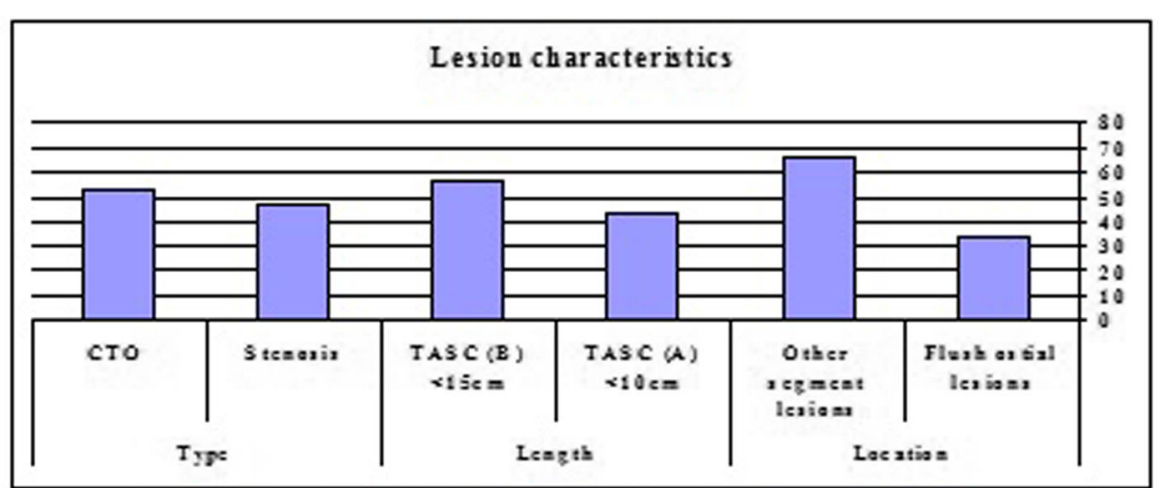

Graph. $\left(4_{A}\right)$ : Lesion characteristics of the studied patients.

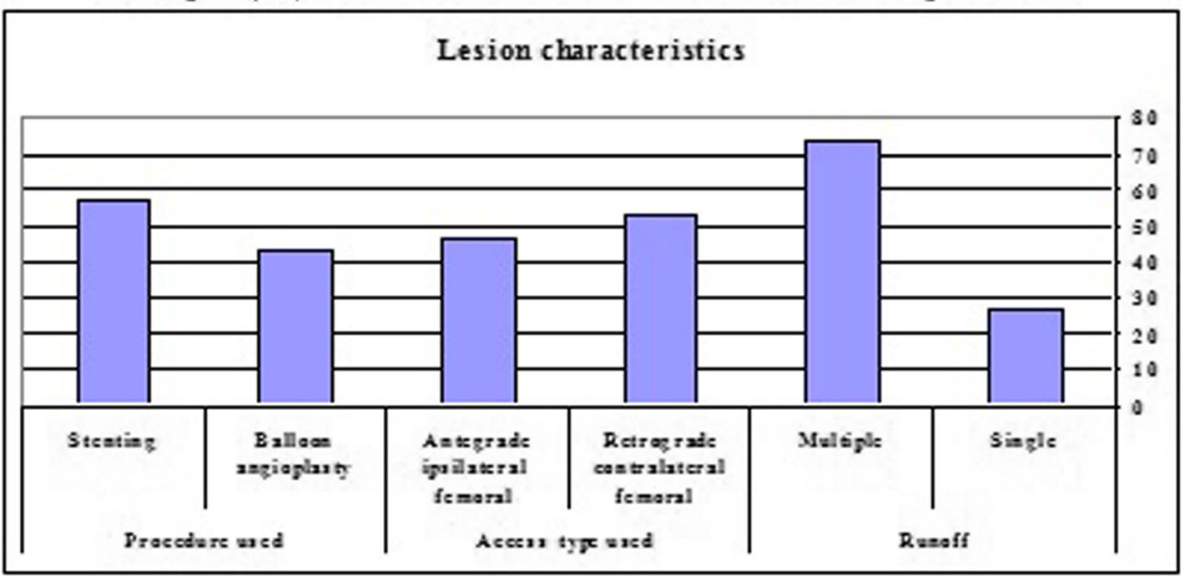

Graph. (4B): Lesion characteristics of the studied patients.

Fig. 9 a, b Lesion characteristics of the studied patients 
Table 5 Types of access used in relation to disease location

\begin{tabular}{|c|c|c|c|c|}
\hline \multirow[t]{2}{*}{ Type of access } & \multicolumn{2}{|c|}{ Group (1): flush ostial lesions $(n=10)$} & \multicolumn{2}{|c|}{ Group (2): other segment lesions $(n=20)$} \\
\hline & No & $\%$ & No & $\%$ \\
\hline Contralateral retrograde femoral & 9 & 30 & 6 & 20 \\
\hline Ipsilateral femoral & 1 & 3.3 & 14 & 46.7 \\
\hline Statistical analysis & \multicolumn{4}{|c|}{$X^{2}=6.7, P=0.03$} \\
\hline
\end{tabular}

Data are presented as numbers, mean $\pm S D$, and percentages

\section{Follow-up}

Clinical follow-up consisted of pulse examination and evaluation of the ulcer or amputation site healing or resolution of infection.

Clinical outcomes, primary patency, secondary patency, and complications following the procedure were reported. All patients were re-examined after 1 week to check for access site complications and to confirm patency.

\section{Statistical analysis}

Analysis of data was done by using the Statistical Package for Social Sciences (SPSS) version 16 (Bristol university in the UK). Quantitative data were presented as mean and standard deviation and were analyzed by ANOVA test. Qualitative data was presented as numbers and percentages and were analyzed by using chi-square. $(P$ value $<0.05)$ was considered significant while $(P$ value $<0.01)$ was considered highly significant. But $(P$ value $>$ 0.05) was considered insignificant.

\section{Results}

This retrospective study was conducted on 30 patients: $20(66.7 \%)$ males and 10 (33.3\%) females with age over 41 years with strata; 41-55 years, 11 (36.7\%); and $\geq 55$ years, 19 (63.3\%) (Table 1, Figs. 6, 7)

The presenting symptoms were as follows: 2 patients (6.7\%) presented with severe claudication pain
(Rutherford category 3), 5 patients (16.7\%) presented with ischemic rest pain (Rutherford category 4), and 16 patients (53.3\%) presented with ischemic ulcers or minor tissue loss (Rutherford category 5) while 7 patients (23.3\%) presented with major tissue loss (Rutherford category 6); note that minor tissue loss needed just debridement or foot sparing amputations, i.e., ray, toe, transmetatarsal, lisfranc, pirogoffs, or Symes (ankle) amputations. Major tissue loss needed major amputation, i.e., above ankle amputation (Table 2).

As regards the risk factors and co-morbidities, 17 (56.7\%) patients were diabetic, 22 (73.3\%) patients were hypertensive, $2(6.7 \%)$ patients had history of previous ischemic heart disease, and 1 (3.3\%) patients had history of previous stroke while 16 (51.7\%) patients had more than one co-morbid disease. Twenty-five (83.3\%) of patients were smokers (Table 3, Fig. 8).

For lesion characteristics, the disease location was either flush ostial lesions in $10(33.3 \%)$ or other SFA segment in 20 (66.7\%). Most of patients, 17 (56.7\%) were suffering from TASC (B) $<15 \mathrm{~cm}$ lesions, and $13(43.3 \%)$ patients were suffering from TASC $(\mathrm{A})<10 \mathrm{~cm}$ lesions of SFA. These target lesions were either stenosis in 14 (46.7\%) patients or chronic total occlusion (CTO) in 16 (53.3\%) patients. Out of these patients, 22 (73.3\%) patients had multiple lesions. Crossing lesion was intraluminally in about 17 (56.7 \%) patients; while in 13 (43.3\%) patients, lesion was crossed subintimally as a

\section{Type of access}

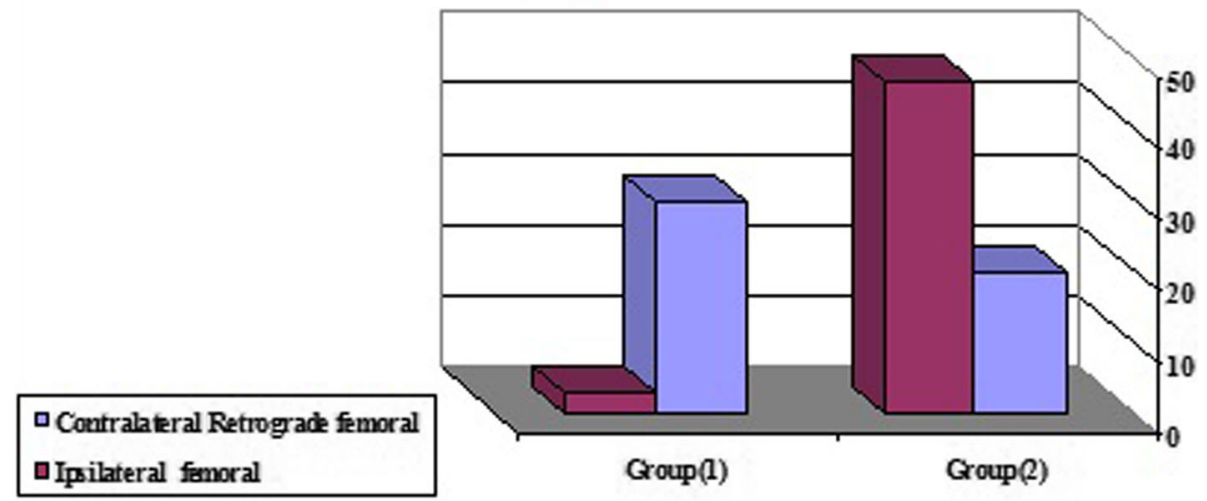

Fig. 10 Types of access used in relation to disease location 
Table 6 Bailout access used in both groups

\begin{tabular}{llllll}
\hline Bailout access & \multicolumn{2}{l}{ Group (1): flush ostial lesions $(n=10)}$. & & Group (2): other segment lesions $(n=20)$ \\
\cline { 2 - 3 } \cline { 5 - 5 } & No & $\%$ & & No \\
\hline Retrograde popliteal & 3 & 10 & 1 & 3.3 \\
Transtibial & 2 & 6.7 & 1 & 3.3 \\
"> one access" & 5 & 16.7 & 2 & 6.7 \\
\hline
\end{tabular}

Data are presented as numbers, mean $\pm S D$, and percentages

bailout procedure. The access used was retrograde femoral in $16(53.3 \%)$ patients and ipsilateral femoral in 14 (46.7\%) patients. Stenting was applied in about 17 (56.7 $\%)$ patients, but $13(43.3 \%)$ cases were treated by balloon angioplasty. Runoff vessels were multiple in about 22 (73.3\%) patients (Table 4, Fig. 9a, b).

The access used in all patients with flush ostial lesion was retrograde femoral access in $9(30 \%)$ and ipsilateral femoral only in 1 (3.3\%); but other segments of SFA, the access used was either retrograde femoral in $6(20 \%)$ patients or ipsilateral femoral in 14 (46.7\%) patients (Table 5, Fig. 10).

The planed procedure was balloon angioplasty applied in all patients but stenting mostly was applied as a bailout procedure. Bailout procedures are defined as procedures used to save the limb or the patient; bailout procedures used for failed access was more in group (1) and included fluoroscopic-guided retrograde popliteal access in $3(10 \%)$ patients and transtibial in $2(6.7 \%)$ patients and one case by duplex-guided posterior tibial artery and the other by open method of anterior tibial artery (Table 6, Fig. 11).

Bailout procedures were done for complications that was in need for immediate intervention; most of these complications were flow-limiting dissection in $18(60 \%)$, thrombosis in 17 (56.7\%), and residual stenosis $\geq 30 \%$ in $13(43.3 \%)$ cases. Perforation or rupture was observed in $9(30 \%)$ cases, and equipment failure was only in 4 (13.3\%) (Table 7, Fig. 12).

As regards the type of bailout procedures used, endovascular intervention was successful in treatment of most of distal SFA complications with limited use in flush ostial complications; residual stenosis $\geq 30 \%$, flowlimiting dissection, perforation or rupture; $100 \%$ in group (2) vs $50 \%$ in group (1) but thrombosis; and $75 \%$ of distal SFA lesions were treated endovascularly vs $40 \%$ of flush ostial lesions. Other complications were treated with successful endovascular intervention, $100 \%$ in both groups (Table 8).

Emergency surgery as a bailout was used for most ostial lesion complications: residual stenosis $\geq 30 \%$, flow-limiting dissection, perforation or rupture, and 50\% in group (1) vs $0 \%$ in group (2). Also, emergency surgery was used in failed endovascular intervention for distal SFA lesions only to treat thrombosis (25\%). (Table 9).

Upon review of bailout procedures outcomes, there were primary outcome parameters; technical success was reported in $96.6 \%$ after endovascular intervention and $61.5 \%$ after surgical treatment. For secondary outcome parameters, clinical response was reported in $91.4 \%$ after endovascular intervention and $46.2 \%$ after surgical treatment. Success rates were more better with endovascular bailout procedures (Table 10).

\section{Discussion}

The determination of the best method of revascularization for treatment of symptomatic peripheral arterial disease (PAD) is based upon the balance between risk of a specific intervention and the degree and durability [10].

The current study was conducted on 30 patients complaining of LL ischemia: age over 41 years with strata; 41-55 years, 11 (36.7\%); and $\geq 55$ years, 19 (63.3\%),

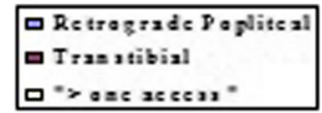

Bailout access in both groups

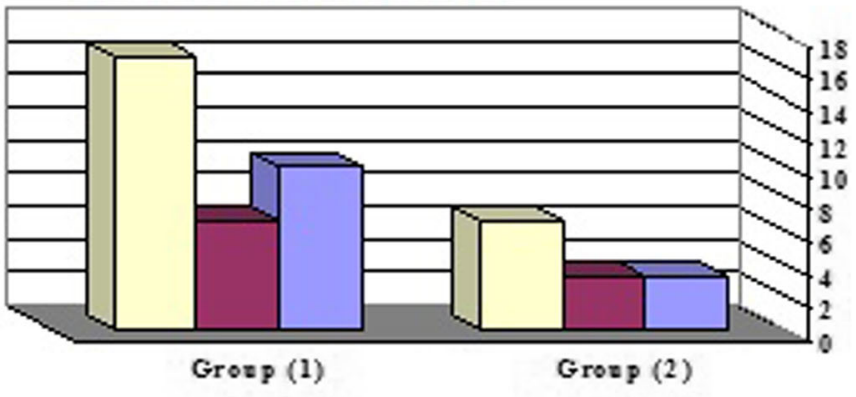

Fig. 11 Bailout access used in both group s 
Table 7 Indications for bailout procedure

\begin{tabular}{lll}
\hline Complications & Findings \\
\cline { 2 - 3 } & No & $\%$ \\
\hline Flow-limiting dissection & 18 & 60 \\
Thrombosis & 17 & 56.7 \\
Residual stenosis $\geq 30 \%$ & 13 & 43.3 \\
Perforation or rupture & 9 & 30 \\
Spasm of distal arteries & 8 & 26.7 \\
Equipment failure & 4 & 13.3 \\
Device embolization & 2 & 6.7 \\
Total complications & 71 & $100 \%$ \\
\hline
\end{tabular}

Data are presented as numbers, percentages, and ranges (note that there more than one complaint in the same patient: total complication number, 71 in 30 patients)

confirming data from epidemiological studies suggesting increased incidence of PAD in aging population. "Selvin et al." reported that the incidence of PAD is $14.5 \%$ in patients $>69$ years [11].

In this study, presenting symptoms (indications of revascularization) were comparable to study on 109 patients done by "Ihnat et al." who reported in his study: indication of SFA angioplasty, claudication in 71 (65\%) patients, ischemic rest pain in $12(11 \%)$ patients, and tissue loss in $26(24 \%)$ patients [12].

Bailout procedures used for failed access was more in group (1) and included retrograde ipsilateral popliteal in $3(10 \%)$ patients and ipsilateral transtibial in $2(6.7 \%)$ patients. "Shi et al." evaluated the efficacy of a dual femoral-popliteal access in CTO of SFA in 21 cases and stated that flush occlusion of SFA presents a unique challenge, in which advance techniques such as retrograde recanalization from popliteal artery are increasingly being used [13].
Ipsilateral transtibial access was used in $2(6.7 \%)$ cases with concomitant popliteal artery lesions; one of these 2 cases is duplex-guided posterior tibial artery that was used and the second case is anterior tibial artery that was used via open method. This access was used successfully when other accesses were failed as mentioned by "Fusaro et al" [14].

Bailout procedures of the current study were done for acute vascular complications that were in need for immediate intervention; Most of these complications were flow-limiting dissection in 18 (60\%), thrombosis in 17 (56.7\%), and residual stenosis $\geq 30 \%$ in $13(43.3 \%)$ cases. Perforation or rupture was observed in $9(30 \%)$ cases, and equipment failure was only in 4 (13.3\%). These were comparable to study done by "Schillinger et al" who reported that acute vascular complications at the endovascular procedure site include arterial perforation, dissection, thrombosis, spasm, side branch occlusion, and equipment failure. Arterial perforation can occur both at the site of balloon angioplasty and distally from the guidewire [15].

Residual stenosis $\geq 30 \%$ was observed in $4(30.8 \%)$ patients in group (1) and in 9 (69.2\%) patients in group (2). This was comparable to results reported by Mikel and Peter [16], who mentioned that during SFA angioplasty, residual stenoses of $30 \%$ or greater may occur with an estimated frequency of $5-10 \%$.The degree of residual stenosis that may be acceptable depends on clinical situation; it may be acceptable in a patient with rest pain and high surgical risk but not in extensive pedal gangrene that needs a femoral-tibial bypass [17].

In the current study, flow-limiting dissections were reported in $6(33.3 \%)$ patients in group (1) and in 12 (66.7\%) patients in group (2). Dissections may be occurred at branch points, in juxtaposition to very bulky or

\section{Indications of bailout procedure}

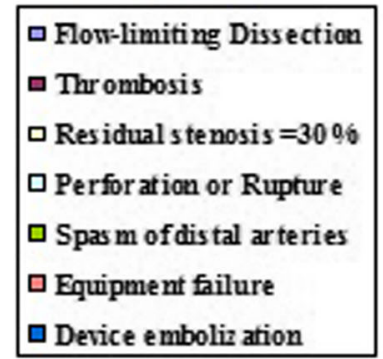

Fig. 12 Indications for bailout procedure

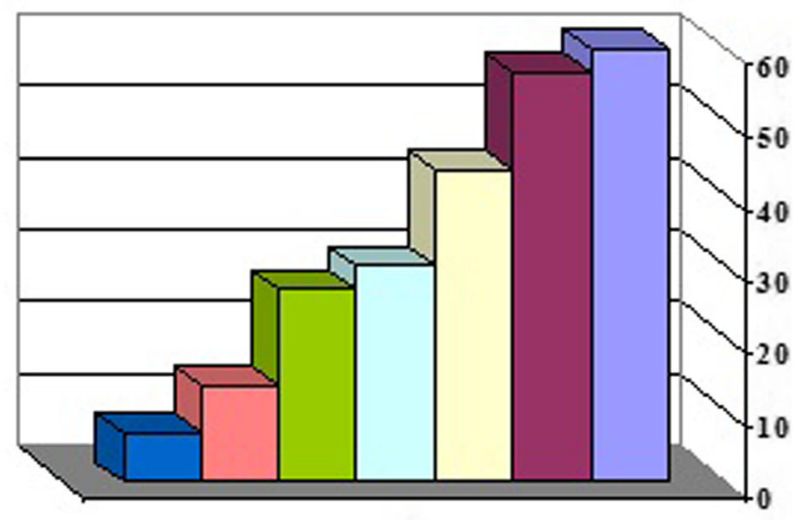

1 
Table 8 Distribution of endovascular treated patients

\begin{tabular}{|c|c|c|c|c|}
\hline \multirow[t]{2}{*}{ Endovascular } & \multicolumn{2}{|c|}{ Group (1): flush ostial lesions $(n=10)$} & \multicolumn{2}{|c|}{ Group (2): other segment lesions ( $n=20$} \\
\hline & $\overline{\mathrm{No}}$ & $\%$ & $\overline{\mathrm{No}}$ & $\%$ \\
\hline Residual stenosis $\geq 30 \%$ & $2 / 4$ & 50 & $9 / 9$ & 100 \\
\hline Flow-limiting dissection & $3 / 6$ & 50 & $12 / 12$ & 100 \\
\hline Perforation or rupture & $2 / 4$ & 50 & $5 / 5$ & 100 \\
\hline Thrombosis & $2 / 5$ & 40 & $9 / 12$ & 75 \\
\hline Equipment failure & $3 / 3$ & 100 & $1 / 1$ & 100 \\
\hline Spasm of distal arteries & $3 / 3$ & 100 & $5 / 5$ & 100 \\
\hline Device embolization & $1 / 1$ & 100 & $1 / 1$ & 100 \\
\hline Total & $16 / 26$ & 61.5 & $42 / 45$ & 93.3 \\
\hline Statistical analysis & \multicolumn{4}{|c|}{$X^{2}=12.7, P=0.02$} \\
\hline
\end{tabular}

Data are presented as numbers, percentages, and using chi-square test $\left(X^{2}\right)$

circumferential plaques, and in arteries with diffuse longitudinal plaque formation without natural cleavage planes, especially if plaque is heavily calcified. The superficial femoral artery, especially at its origin and in the adductor canal, tends to dissect $[17,18]$.

Perforations or rupture was observed in 4 (44.4\%) patients in group (1) and in $5(55.6 \%)$ patients in group (2). Perforation has been reported in $0-2.3 \%$ of patients in a study done by "Schillinger et al" [15]. In a study by "Hayes," 1409 patients undergoing peripheral angioplasty were evaluated and $52(3.7 \%)$ had suffered a perforation [19].

In thrombosis and distal embolization, the patient starts off with one problem (the lesion) and ends up with two problems (a partially treated and an ischemic or occluded outflow bed); this conditions were suspected when there was filling defects at some location distal to angioplasty site or patients exhibited new-onset claudication or pain at rest [16], and this was reported in the current study in $5(29.4 \%)$ patients in group (1) and in $12(70.6 \%)$ patients in group (2); this could be explained by sheath thrombosis with distal trash or as a result of instrumentation of a friable atherosclerotic complex lesions [20].

Upon review of spasm of distal arteries, it was observed in about $3(37.5 \%)$ patients in group (1) and 5 (62.5\%) patients in group (2). Most of these patients were relatively young as mentioned by "Zeller et al." who stated that "The occurrence of arterial vessel spasm appears to be more common in younger patients. Arterial spasm rarely leads to serious complications during angioplasty, However, severe symptoms of pain may occur" [21].

As regards type of bailout procedures used, endovascular intervention was successful in treatment of most of distal SFA lesions complications (93.3\%) with limited use in flush ostial lesions complications (61.5\%). But emergency surgery, as a bailout, was used for most ostial lesion complications or failed of endovascular interventions. This depended on the fact that working distance in flush ostial lesion was short making endovascular intervention difficult [18].

The development of intravascular stents had made it possible to successfully treat post angioplasty dissection

Table 9 Distribution of surgically treated patients

\begin{tabular}{lllll}
\hline Surgery & \multicolumn{2}{l}{ Group (1): flush ostial lesions $(n=10)$} & & Group (2): other segment lesions $(n=20)$ \\
\cline { 2 - 3 } \cline { 5 - 5 } & No & $\%$ & No & 0 \\
\hline Residual stenosis $\geq 30 \%$ & $2 / 4$ & 50 & $0 / 9$ & 00 \\
Flow-limiting dissection & $3 / 6$ & 50 & $0 / 12$ & 0 \\
Perforation or rupture & $2 / 4$ & 60 & $3 / 12$ & 25 \\
Thrombosis & $3 / 5$ & 00 & $0 / 1$ & 00 \\
Equipment failure & $0 / 3$ & 00 & $0 / 5$ & 00 \\
Spasm of distal arteries & $0 / 3$ & 00 & $0 / 1$ & 00 \\
Device embolization & $0 / 1$ & 38.5 & $3 / 45$ & 6.7 \\
Total & $10 / 26$ & & &
\end{tabular}

Data are presented as numbers, percentages, and using chi-square test $\left(X^{2}\right)$ 
Table 10 Outcomes of the treated patients

\begin{tabular}{llllll}
\hline \multirow{2}{*}{ Outcomes } & \multicolumn{2}{l}{ Endovascular treated group } & & \multicolumn{2}{l}{ Surgically treated group } \\
\cline { 2 - 3 } \cline { 5 - 6 } & No & $\%$ & No & $\%$ \\
\hline Technical success & $56 / 58$ & 96.6 & $8 / 13$ & 61.5 \\
Clinical response & $53 / 58$ & 91.4 & $6 / 13$ & 46.2 \\
\hline
\end{tabular}

Data are presented as numbers, percentages, and ranges

when it was recognized on the angiographic table. Nevertheless, it added cost. Arterial rupture is one complication that may result in death; treatment of resultant perforation or rupture was mainly by endovascular intervention that was successful in $7(77.9 \%)$ patients, $2(50 \%)$ patients in group (1), and $5(100 \%)$ in group (2); conservative treatment, in the form of manual compression and systemic anticoagulation reversal, was reported in one patient of group (1) but adjunctive endovascular therapy consisted of balloon tamponade in 4 patients: one of them in group (1) and covered stents in 2 patients; this results were comparable to the study done by "Hayes" [19] who reported 27/52 (51.9\%) perforations were completed successfully by endovascular intervention.

Clinically significant post angioplasty thrombosis and embolization may result in organ or limb loss. Successful endovascular intervention in treatment of thrombosis was reported in $2(40 \%)$ patients in group (1) and 9 (75\%) patients in group (2). The bailout procedures used were sheath removed, flushed, and reinserted over introducer wire in 4 patients and thrombolytic therapy in 4 patients in addition to stabilization of the angioplasty site by stent placement and the remaining 3 patients were treated by thrombectomy using fogarty over the wire [17].

In the present study, another source of procedural complications was related to device failure, about 3 (75\%) patients in group (1) and 1 (25\%) patients in group (2) as mentioned by "Zeller et al." and "Schillinger et al." This included broken wire and embolization that were reported only in 2 patients; one in each group, these patients were treated using vascular snare and grasping forceps, failed balloon deflation was observed in one patient that was managed by balloon overinflation, and lastly, balloon rupture and embolization were observed during dilation of a sharp or heavily calcified lesion in one patient that was treated with a stent, and the lesion through the stent was dilated [15, 21].

Conversion from endovascular intervention to open surgery does not mean lost face or lost respect. Surgery was applied only in group (1) to treat residual stenosis $\geq$ $30 \%$ in $2(50 \%)$ patients and flow-limiting dissection in 3 (50\%) patients by bypass surgery in 3 patients or interposition grafts in 2 patients and perforation or rupture in $2(50 \%)$ patients by direct closure of perforation in one patient and vein patch closure in rupture in the other patient after proximal and distal control. Surgery was applied in group (2) to treat thrombosis in $3(25 \%)$ patients by successful open thrombectomy in one patient and bypass surgery in 2 patients. This result was comparable to study done by "Hayes" [19] who reported that 6/25 (24\%) underwent bypass surgery.

Groin hematoma was reported in two patients and was managed with conservative treatment.

Prevention is better than cure. So, prevention of the abovementioned complications can be done by training for single perfect pass of the entry needle that is a must, proper selection of the puncture site, and the suitable instruments (proper sheath, wires, catheters, and balloons with proper size and length). Proper heparin therapy was performed to prevent thrombosis with distal embolization.

\section{Conclusions}

Bailout procedures are procedures used to save the limb or the patient. Evolving endovascular strategies embrace new technologies in an attempt to improve the safety and efficacy of revascularization procedures for lower extremity arterial occlusive disease.

\section{Abbreviations \\ SFA: Superficial femoral artery; TASC II: TransAtlantic Society Consensus II; Fig.: Figure; 6F: 6French; SPSS: Statistical Package for Social Sciences; CTO: Chronic total occlusion; PAD: Peripheral arterial disease}

\section{Acknowledgements}

Not applicable.

\section{Authors' contributions}

"E A" was the main and corresponding author who interpreted the patient data regarding the intervention done and was major contributor in writing the manuscript. "O A" was revised the manuscript. "A S" was contributor in writing the manuscript and supervisor. " $\mathrm{H} Z$ " was major contributor in writing the manuscript and supervisor. All authors read and approved the final manuscript.

\section{Funding}

This study had no funding from any resource.

\section{Availability of data and materials}

The datasets used and/or analyzed during the current study are available from the corresponding author on reasonable request that was taken from Cairo university hospitals archives. 


\section{Ethics approval and consent to participate}

This study was approved by the Research Ethics Committee of the Faculty of Medicine at Cairo University in Egypt on June 2015; reference number of approval: I-080315 and consent to participate is not applicable, as this paper was retrospective.

\section{Consent for publication}

Not applicable.

\section{Competing interests}

The authors declare that they have no competing interests.

Received: 30 July 2019 Accepted: 11 March 2020

Published online: 31 March 2020

\section{References}

1. Axisa B, Fishwick G, Bolia A (2002) Complications following peripheral angioplasty. Ann. R. Coll. Surg. Engl. 84:39-42

2. Muradin G, Bosch J, Stijnen T, Hunink M (2005) Balloon dilatation and stent implantation for treatment of femoropopliteal arterial disease: meta-analysis. Radiology. 6:12-15

3. Daniel G, Timur P, Jessica M (2014) Percutaneous angioplasty with or without stenting for lower extremity occlusive disease in current therapy in vascular surgery and endovascular surgery $5^{\text {th }}$ ed. By Stanley et al. 2(5):537539

4. Adam D, Beard J, Cleveland T (2008) Bypass versus angioplasty in severe ischemia of the leg (BASIL): multicentre randomized controlled trial. Lancet. 2:23-36

5. Baril D, Marone L, Kim J (2008) Outcomes of endovascular intervention for TASC II B and C femoropopliteal lesions. J. Vasc. Surg. 48(3):627-633

6. Morgan R, Walser E (2010) Handbook of angioplasty and stenting procedures, 97 Techniques in Interventional Radiology. DOI. 7:2-6

7. Kiernan T, Ajani A, Yan B (2010) Management of access site and systemic complications of percutaneous coronary and peripheral interventions. J. Invasive Cardiol. 20(9):463-469

8. Zeller T, Baumgartner I, Scheinert D (2014) IN.PACT DEEP trial investigators Drug-eluting versus standard balloon angioplasty for infrapopliteal arterial revascularization in critical limb ischemia: 12-month results from the IN. PACT DEEP randomized trial. J. Am. Coll. Cardiol. 64(15):1568-1576

9. Diehm N, Pattynama P, Jaff M, Becker G, Hopkins L (2008) Clinical endpoints in peripheral endovascular revascularization trials: a case for standardized definitions. Eur. J. Vasc. Endovasc. Surg. 36(4):19-40

10. Norgren L, Hiatt W, Dormandy J, TASC II Working Group (2007) Inter-society consensus for the management of peripheral arterial disease. Int. Angiol. Jun 26(2):81-97

11. Selvin E, Marinopoulos S, Berkenblit G (2004) Meta-analysis: glycosylated hemoglobin and cardiovascular disease in diabetes mellitus. Ann. Intern. Med. 141(6):421-431

12. Innat M, Duong T, Taylor C, Leon R, Mills L (2008) Contemporary outcomes after superficial femoral artery angioplasty and stenting: the influence of TASC classification and runoff score in J. VASC. SURG. 4(5):967-974

13. Shi W, Yao Y, Wang W (2014) Combined antegrade femoral artery and retrograde popliteal artery recanalization for chronic occlusions of the superficial femoral artery. J. Vasc. Interv. Radiol. Sep. 25(9):1363-1368

14. Fusaro M, Dalla PL, Biondi-Zoccai G (2006) Retrograde posterior tibial artery access for below-the-knee percutaneous revascularization by means of sheathless approach. Minerva Cardioangiol 54:773-777

15. Schillinger M, Sabeti S, Loewe C, Dick P, Amighi J, Mlekusch W (2006) Balloon angioplasty versus implantation of nitinol stents in superficial femoral artery. N. Engl. J. Med. 354(18):187-188

16. Mikel S. and Peter L. (2010): Infrainguinal disease; endovascular treatment in Rutherford's vascular surgery, $7^{\text {th }}$ ed. By Cronenwett J. and Johnston K. Chapter 110: 5890

17. Schneider P. (2009): Endovascular skills, guidewire and catheter skills for endovascular surgery; $3^{\text {rd }}$ Edition; p: 15-41.

18. Sambol E. and Mckinsey J. (2014): Local complications: endovascular in Rutherford vascular surgery, $8^{\text {th }}$ ed:; printed in china; 1 (46): 704-710.

19. Hayes P (2002) Arterial perforation during infrainguinal lower limb angioplasty does not worsen outcome: results from 1409 patients. J. Endovasc. Ther. 9:422-427
20. Bauermeisto $G$ (2001) Endovascular stent-grafting in treatment of superficial femoral artery occlusive disease. J. Endo. Ther. 8:315-320

21. Zeller T, Tiefenbacher C, Steinkamp H (2008) Nitinol stent implantation in TASC Aand B superficial femoral artery lesions: the femoral artery conformexx trial (FACT). J. Endovasc. Ther. 15(4):390-398

\section{Publisher's Note}

Springer Nature remains neutral with regard to jurisdictional claims in published maps and institutional affiliations.

\section{Submit your manuscript to a SpringerOpen ${ }^{\circ}$ journal and benefit from:}

- Convenient online submission

- Rigorous peer review

- Open access: articles freely available online

- High visibility within the field

- Retaining the copyright to your article

Submit your next manuscript at $\boldsymbol{\nabla}$ springeropen.com 